\title{
ОТВЕТСТВЕННОСТЬ ЗА НАРУШЕНИЯ ПРАВИЛ ИСПОЛЬЗОВАНИЯ ВОЗДУШНОГО ПРОСТРАНСТВА
}

\section{LIABILITY FOR VIOLATIONS OF THE RULES FOR USE OF THE AIRSPACE}

\section{A. Shashkin}

Summary. The article highlights the features of responsibility for violation of the rules for the use of airspace. The relevance of the study lies in the fact that violations of the established rules can lead to grave consequences in the form of harm to life or health, but the mechanism of bringing to responsibility cannot be called perfect. As a result, the identification of problems and the development of ways to solve them are relevant. The foregoing predetermined the scientific significance of this study. The aim of the study is to analyze issues related to prosecution for violation of the rules for the use of airspace, the main method is the formal legal method and the method of system analysis. The article was written using literature in the form of articles on the relevant topic and monographic publications, the current legislation was actively applied. The study revealed that the current legislation in this area is hardly perfect, which predetermines the need for its improvement. Against this background, the conclusion is formulated and substantiated that it is advisable to supplement and amend the legislation taking into account the recommendations set out in this article. It is suggested that this will also reduce the number of crimes in the considered area.

Keywords: air space, flight, unmanned aerial vehicle, a responsibility, permission.

\section{Введение}

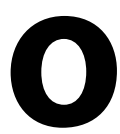

тветственность за нарушения правил использования воздушного пространства на современном этапе развития регламентируется ст. 271.1 Уголовного кодекса РФ (далее-УК РФ), введенной в состав уголовного законодательства относительно недавно, в 2011 году [1]. Так, в соответствии с данной статьей, использование воздушного пространства Российской Федерации без разрешения в случаях, когда данное разрешение требуется в соответствии с законодательством, если это деяние повлекло по неосторожности причинение тяжкого вреда здоровью или смерть человека, наказывается лишением свободы на срок до 5 лет с обязательным лишением заниматься определенной деятельностью или занимать определенные должно-

\author{
Шашкин Александр Андреевич \\ Аспирант, Российский университет транспорта \\ (МИИТ) Юридический институт, Москва \\ Shashkin1@list.ru
}

Аннотация. В статье освещаются особенности ответственности за нарушение правил использования воздушного пространства. Актуальность исследования заключается в том, что нарушения установленных правил могут повлечь тяжкие последствия в виде причинения вреда жизни или здоровью, однако механизм привлечения к ответственности нельзя назвать совершенным. Как следствие, актуальностью обладает выявление проблем и разработка путей их решения. Вышесказанное предопределило научную значимость данного исследования. Целью исследования является анализ вопросов, связанных с привлечением к ответственности за нарушение правил использования воздушного пространства, основным методом является формально-юридический метод и метод системного анализа. Статья была написана с использованием литературы в виде статей соответствующей тематики и монографических изданий, активно применялось действующее законодательство. В рамках исследования было выявлено, что действующее законодательство в указанной сфере едва ли является совершенным, что предопределяет необходимость его совершенствования. На этом фоне формулируется и обосновывается вывод о том, что дополнение и изменение законодательства целесообразно проводить с учетом рекомендаций, изложенных в данной статье. Высказывается предположение, что это также позволит снизить количество преступлений в рассмотренной области.

Ключевые слова: воздушное пространство, полет, беспилотный летательный аппарат, ответственность, разрешение.

сти сроком до трех лет. Также данное деяние имеет квалифицированный состав, правовыми последствиями которого будет являться смерть двух или более лиц (по неосторожности). За квалифицированный состав санкция ужесточается и будет представлять собой лишение свободы на срок до 7 лет и лишением права заниматься определенной деятельностью и занимать определенные должности сроком до трех лет.

\section{Результаты}

Представляется, что внедрение данного состава преступления в текст Уголовного кодекса РФ во многом обусловлено тем, что нарушение правил в сфере использования воздушного пространства нашей страны может порождать весьма опасные последствия, в част- 
ности, причинение тяжкого вреда здоровью или смерть граждан, что прямо указано в диспозиции ст. 271.1 УК РФ. Как следствие, в качестве объекта данного преступления стоит рассматривать безопасность использования воздушного пространства РФ, под которой стоит понимать характеристику установленного порядка использования воздушного пространства РФ. В свою очередь, объективной стороной будет использование воздушного пространства без разрешения, если такое разрешение являлось объективной необходимостью. Отсюда возникает закономерный вопрос: что необходимо понимать под использованием воздушного пространства и какое использование будет образовывать состав преступления и выступать в качестве основания для привлечения к ответственности? Полагаем, что использование в этом контексте представляет собой деятельность, в рамках которой осуществляется перемещение в воздушном пространстве различных объектов материального мира и строительство ряда сооружений [3, с. 136]. Так, к объектам объективной действительности относятся воздушные суда или, например, ракеты. Кроме того, под использованием воздушного пространства в указанном случае стоит понимать деятельность, в рамках которой происходят электромагнитные и иные излучения, проведение взрывных работ, ухудшение видимости, необходимой для полетов. В связи с этим, использованием воздушного пространства может являться любая деятельность, которая представляет угрозу безопасности воздушного движения. Применительно к составу преступления, указанного в ст. 271.1 УК РФ, данная деятельность должна осуществляться без необходимого разрешения. Ярким примером такой ситуации является незаконное использование беспилотных летательных аппаратов, так как в случае, если их эксплуатация привела к последствиям, которые указаны в ст. 271.1 УК РФ, применению будут подлежать те меры ответственности, которые указаны в данной статье. Очевидно, что вся деятельность, речь о которой ведется в рассматриваемом нами случае, может быть ограничена или запрещена.

Также рассматривая особенности ответственности за нарушение прав использования воздушного пространства стоит отметить, что использование воздушного пространства за пределами РФ, но на тех территориях, которые являются подконтрольными нашей стране и при наступлении последствий, указанных в ст. 271.1 УК РФ, также является наказуемым, но к ответственности виновные лица будут привлечены в соответствии с требованиями, которые содержатся в Конвенции о международной гражданской авиации.

Решая вопрос о привлечении к ответственности за совершение указанного деяния также стоит обращать внимание на то, что воздушное пространство на территории нашей страны дифференцируется на определенные виды, а решающее значение имеет тот факт, в какой конкретно разновидности воздушного пространства была осуществлена деятельность, угрожающая безопасности полетов. Так, класс воздушного пространства «А» означает, что в данном пространстве разрешены полеты, однако выполняться они должны только по правилам полетов по специальным приборам. Как следствие, все воздушные суда, которые летают в данном пространстве обеспечены диспетчерским обслуживанием и не ограничены в скорости полетов. Представляется вполне естественным, что в данном пространстве полеты будут выполняться при наличии разрешения на использование воздушного пространства. В свою очередь, в воздушном пространстве класса «С» разрешаются полеты, которые будут выполняться по правилам полетов по приборам, а также по правилам визуальных полетов. Отличие от класса «A» состоит в том, что в этом случае применимы ограничения в скорости, которая не может составлять более 450 км/ч. Также существует воздушное пространство класса «G», в рамках которого разрешены полеты, на осуществление которых не требуется разрешение на использование воздушного пространства и в отношении которых ограничения скорости не применяется. Как следствие, если самолет, не имеющий допуска для полетов в воздушном пространстве класса «А», будет замечен в указанном воздушном пространстве, лица, ответственные за этот полет вполне могут быть привлечены к ответственности по ст. 271.1 УК РФ. Одновременно с этим, в рамках привлечения к ответственности в указанных случаях стоит учитывать исключения, которые предусмотрены в федеральных правилах. Так, в соответствии с данным документом, не обязательно получать разрешение на полет или на проведение работ в воздушном пространстве класса «A» и «С» в следующих случаях. Во-первых, при отражении воздушного нападения и вторжения на территорию РФ. Во-вторых, В случае пресечения или предотвращения нарушения государственной границы РФ и защиты (охраны) ее экономических интересов. В-третьих, в случае пресечения или раскрытия преступлений и оказании помощи в чрезвычайных ситуациях (техногенного или природного характера). В-четвертых, если воздушное пространство было использовано для поиска и для спасания пассажиров и экипажей воздушных судов, которые терпят или потерпели бедствие, для поиска и эвакуации с места посадки космонавтов и спускаемых космических объектов и их аппаратов. И, наконец, в-пятых, при использовании воздушного пространства данных классов в целях предотвращения и пресечения нарушений правил использования воздушного пространства. Как следствие, использование воздушного пространства в целях, указанных выше, состав преступления, предусмотренный ст. 271.1 УК РФ не образует 
и не порождает привлечение задействованных лиц к ответственности.

Что касается выдачи разрешений на использование воздушного пространства, то ее выдачей занимаются органы обслуживания воздушного движения, причем указанный орган занимается выдачей разрешений и на эксплуатацию беспилотных летательных аппаратов (далее БПЛА) и на осуществление деятельности, рассмотренной выше. Очевидно, что полет или осуществление деятельности, угрожающей безопасности полетов, в отсутствие данного разрешения является основанием для привлечения лиц к ответственности (при наступлении последствий, указанных в санкции ст. 271.1 УК РФ).

Представляется, что субъективная сторона данного преступления характеризуется умышленной формой вины. Характеристика прямого умысла содержится в ч. 2 ст. 25 УК РФ. Так, в соответствии с данным пунктом, преступление признается совершенным с прямым умыслом, если лицо осознавало общественную опасность своих действий (бездействия), предвидело возможность или неизбежность наступления общественно опасных последствий и желало их наступления. Из данного определения можно выделить три основных признака прямого умысла. Во-первых, в данном случае лицо осознает общественную опасность своих действий (бездействия). Во-вторых, лицо предвидит возможность или неизбежность последствий. И, наконец, в-третьих, лицо желает наступления данных неблагоприятных последствий. Полагаем, что первые два признака характеризуют интеллектуальную сферу психической деятельности, в то время как третий признак, представленный в виде желания наступления преступных последствий - волевую сферу. Таким образом, интеллект отражает и воспроизводит реальность, в то время как воля показывает отношение лица к происходящим событиям. Как следствие, лицо должно осознавать, что его действия создают угрозу для безопасности полетов так как нарушают правила использования воздушного пространства, однако желает наступления таких последствий, например, осознанно нарушая правила использования воздушного пространства РФ. Одновременно с этим, цель и мотив этого преступления не будут оказывать влияния на его квалификацию, что важно учитывать в рамках решения вопроса о привлечении к ответственности.

\section{Обсужление}

Несмотря на то, что правила использования воздушного пространства установлены на законодательном уровне и применяются на территории нашей страны достаточно давно, на современном этапе развития можно наблюдать различные спорные и проблемные аспекты в сфере привлечения к ответственности по ст. 271.1 УК РФ. Рассмотрим данные проблемные моменты более детально.

Так, первым проблемным моментом видится то, что в настоящее время нет легального определения понятия «беспилотный летательный аппарат», однако владельцы именно этих агрегатов становятся самыми частыми нарушителями правил использования воздушного пространства. Однако как привлечь к ответственности владельца этого аппарата в отсутствие критериев отнесения того или иного аппарата к беспилотным? Умалять значимость данной проблемы было бы ошибочным, а ее наличие подтверждается в научной литературе. Так, как справедливо отмечает А.И. Чучаев, «определение, которое сегодня содержится в Воздушном кодексе РФ едва ли можно признать в качестве разработанного и исчерпывающего, так как им не охвачены виды летальных аппаратов, в том числе, тех, которые имеют смешанную систему управления» [4, с. 181]. Не согласиться с этой точкой зрения весьма затруднительно. Как следствие, необходимостью является разработка и последующее закрепление в действующем законодательстве определения понятия «беспилотный летательный аппарат».

Вторым проблемным аспектом выступает то, что на современном этапе развития не закреплены требования к согласованию маршрутов БПЛА в связи с чем, они не только часто нарушают правила использования воздушного пространства, но и уходят от ответственности в связи с тем, что требования относительно к оборудованию БПЛА и их маршруту сегодня не установлены. Это явно свидетельствуют о необходимости внесения изменений и дополнений в Воздушный кодекс РФ (далее-ВК РФ) [2].

Следующий проблемный аспект состоит в том, что в настоящее время не установлена ответственность за нарушение порядка программирования БПЛА и контроля над тем, каким образом программные средства обеспечивают функционирование БПЛА. Полагаем, что этот момент требует дальнейшего научного осмысления и последующего законодательного закрепления [5, с. 24].

\section{Зак^ючение}

В завершении стоит отметить, что судебная практика по данному вопросу в нашей стране не сформирована, в связи с чем, суды могут испытывать определенные трудности при рассмотрении дел данной категории. Однако целесообразно предположить, что на фоне планомерного совершенствования действующего законодательства, количество указанных 
ЛИТЕРАТУРА

1. Уголовный кодекс Российской Федерации от 13.06.1996 N63-Ф3 (ред. от 01.07.2021) // Собрание законодательства РФ. — 1996. — N25.—Cт. 2954.

2. Воздушный кодекс Российской Федерации от 19.03.1997 N60-Ф3 (ред. от 02.07.2021) // Собрание законодательства РФ.— 1997.— N12.—Cт. 1383.

3. Черненко Т.Г. Квалификация преступлений: вопросы теории и практики: монография.—М.: Проспект, 2020-208 с.

4. Чучаев А.И. Транспортные преступления: проект новый-недостатки старые // Актуальные проблемы российского права. — 2019. — № 10 (107). — C. $172-190$.

5. Я Ямщиков В.А. Беспилотные летательные аппараты // Техническая эксплуатация водного транспорта: проблемы и пути развития. — 2019.— № 5.— C. $22-25$.

(c) Шашкин Александр Андреевич ( Shashkin1@list.ru).

Журнал «Современная наука: актуальные проблемы теории и практики»

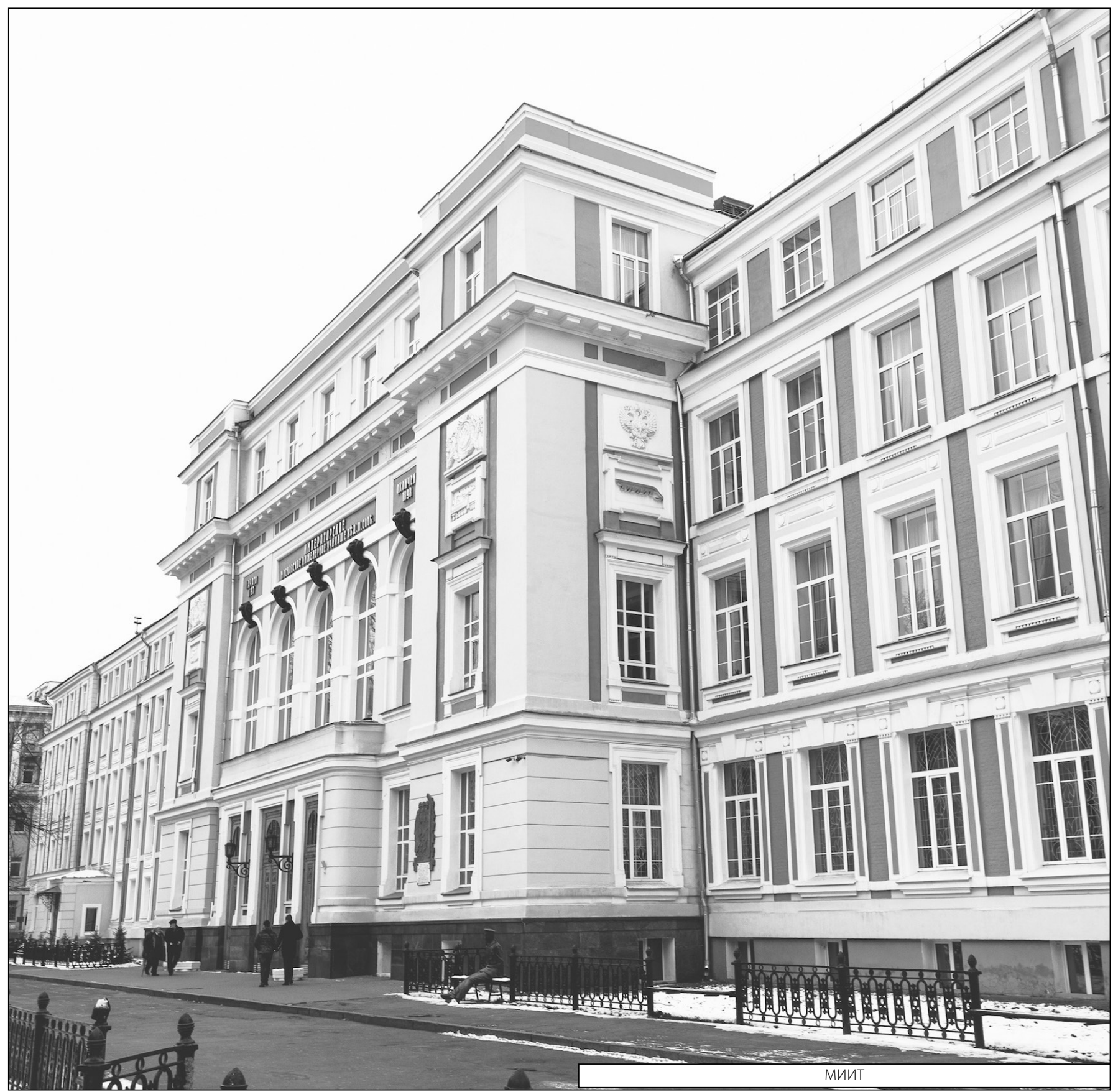

